\title{
Fragmenta latina operis Isaaci Ninivitae Fragmenta latina operis Isaaci Ninivitae
}

\author{
César Nardelli Cambraia* \\ Universidade Federal de Minas Gerais, Belo Horizonte, MG, Brasil
}

\begin{abstract}
Resumo: Este trabalho tem como objetivo dar a conhecer o texto de nove testemunhos fragmentários inéditos da tradução latina da obra de Isaac de Nínive: cód. XIV G 17, Biblioteca Nacional (Praga); cód. M I 159, Biblioteca Científica (Olomouc); cód. 996, Biblioteca Mazarina (Paris); cód. C 631, Biblioteca Universitária (Uppsala); cód. A XI 72, Biblioteca Universitária (Basileia); cód. A X 102, Biblioteca Universitária (Basileia); cód. A XI 71, Biblioteca Universitária (Basileia); cód. GB 8 76, Arquivo Histórico da Cidade (Colônia); e cód. GB $8^{\circ}$ 155, Arquivo Histórico da Cidade (Colônia). Adotaram-se critérios de edição paleográfica, a fim de permitir um estudo mais aprofundado desses registros. $\mathrm{O}$ conhecimento das versões presentes nesses testemunhos permitiu enquadrar parte deles na tradição latina da obra, evidenciando-se variantes e identificando-se erros conjuntivos e separativos.
\end{abstract}

Palavras-chave: Isaac de Nínive. Língua Latina. Crítica Textual. Idade Média.

\begin{abstract}
This paper has as objective to let know the text of nine unpublished fragmentary testimonies of the Latin translation of Isaac of Nineveh's work: cod. XIV G 17, National Library (Prague); cod. M I 159, Scientific Library (Olomouc); cod. 996, Mazarine Library (Paris); cod. C 631, University Library (Uppsala); cod. A XI 72, University Library (Basel); cod A X 102, University Library (Basel); cod. A XI 71, University Library (Basel); cod. GB 8o 76, Historical Archive of the City (Cologne); and cod. GB 8o 155, Historical Archive of the City (Cologne). Criteria of paleographical edition were adopted to allow further study of these documents. Knowing the versions present in these testimonies allowed part of them to be framed in the Latin tradition of the work, highlighting variants and identifying conjunctive and separative errors.
\end{abstract}

Keywords: Isaac of Nineveh. Latin Language. Textual Criticism. Middle Ages.

\section{INTRODUÇÃO}

Isaac de Nínive, asceta que viveu no Oriente Médio no séc. VII, escreveu obras que tiveram grande difusão pelo mundo nos séculos seguintes através de sua tradução para diversas línguas diferentes. Em um dos vários caminhos percorridos, suas obras foram traduzidas do siríaco para o grego entre os sécs. VIII e IX e, deste para o latim, por volta de fins do séc. XIII (seguramente antes de 1270) ${ }^{1}$.

Segundo o estado atual da recensão da tradição latina da obra Isaac de Nínive, essa tradição compõe-se de 105 testemunhos manuscritos supérstites (além de 8 atestados mas não localizados) e 13 edições impressas (Cambraia, 2013-2014, p. 20-23, com atualizações aqui). Dos 100 manuscritos listados em Cambraia (2013-2014),

\footnotetext{
* Professor Titular de Filologia Românica, Faculdade de Letras, Universidade Federal de Minas Gerais, Belo Horizonte, Minas Gerais (MG), Brasil; nardelli@ufmg.br

${ }^{1}$ Para informações mais detalhadas sobre a história de Isaac de Nínive e a difusão de sua obra, cf. Brock (1999-2000), Chialà (2002) e Cambraia (2000, 2013-2014, 2017).
} 
devem-se excluir dois itens: identificou-se que o cód. lat. class. II 61 da Biblioteca Marciana (Veneza) consiste em cota antiga do já computado cód. lat. class. VII 4 da mesma instituição e que o cód. CCI (205) do Mosteiro de Santa Scolastica (Subiaco) contém a obra de Isaac de Stella (Migne, 1855, col. 1713), e não de Isaac de Nínive. Deve-se corrigir também a localização do códice de cota Fondo Conv. Soppr. 399, que não se encontra na Bibl. Nac. Central de Florença, mas sim na Medicea Laurenziana na mesma cidade. Além dos 98 registrados anterioramente, foram identificados mais 7 recentemente: Bibl. S. Convento (Assis), 593, séc. XIV, ff. 78v-80v; Bibl. Riccardiana (Florença), Ricc. 434, séc. XIV, ff. 195r-263r; Bibl. Municipal (Mainz), I 306, séc. XIVXV, ff. 154v-161v e 168v-170r; Bibl. Universitária (Gênova), A.III.24, séc. XV, ff. 20r20v; Biblioteca Civica (Pádua) C.M. 75, s. XV (primeiro quarto); Bibl. (Gdańsk), Mar. F. 228, séc. XV (princ.), ff. 132r-161r; e Bibl. Municipal (Metz), 624, [s.d.], ff. 129r130v (foliação moderna, ff. 124r-125r). Às 12 edições impressas listadas no referido estudo, deve-se acrescentar uma outra: Marguerin de la Bigne, Magna Bibliotheca Veterum Patrum et Antiquorum Scriptorum Ecclesiasticorum, Paris, 1644, t. V, coll. 483-532.

A tradição latina manuscrita é composta por testemunhos que apresentam diferenças em termos da integralidade do texto, da presença de seções agregadas e da ordenação de capítulos. situações:

No que se refere à integralidade do texto, é possível reconhecer as seguintes

a) versão integral: versão integral do texto da tradução latina correspondendo a 28 capítulos da tradução grega (p. ex., cód. 311 da Biblioteca de Arezzo); ou

b) versão não integral: versão do texto com falta de alguma parte.

A versão não integral, por sua vez, pode apresentar-se como tal em função da:

a) ausência contínua de capítulos a partir de certo ponto do texto (p. ex., cód. 489 da Bibl. S. Convento de Assis, com interrupção ao final do c. 17);

b) ausência descontínua de capítulos inteiros ao longo do texto (p. ex., cód. A IX 91, da Biblioteca Universitária da Basiléia, com ausência de 6 capítulos inteiros);

c) ausência de trechos distribuídos ao longo de diferentes capítulos do texto (p. ex., cód. CXXIV/2-8d da Biblioteca Pública de Évora);

d) seleção de poucos ou apenas um capítulo (p. ex., cód. XIV G 17 da Biblioteca Nacional de Praga, com apenas o capítulo final);

e) seleção de poucas ou apenas uma frase (p. ex., cód. GB $8^{\circ} 155$ do Arquivo Histórico da Cidade de Colônia, com apenas uma frase da obra).

Além dessas diferenças, os textos se distinguem em função da presença de seções agregadas (Cambraia, 2020, p. 17), que podem ser:

a) índice (ausente, no início ou no final);

b) dedicatória (ausente, no início ou no final);

c) prólogo (ausente, tipo 1, tipo 2, tipo 3);

d) interpolação de texto de João Cassiano (ausente ou presente);

e) apêndice com frases de origem diversa (ausente ou presente); e

f) versão condensada da obra (ausente, tipo 1 ou tipo 2). 
É também digno de menção que os textos se diferem em termos de ordenação de alguns capítulos específicos: o capítulo iniciado por Fortitudinem, p. ex., aparece deslocado para o final em alguns testemunhos (p. ex., cód. Plut. LXXXIX/96 da Bibl. Med. Laur. de Florença).

Em função da atuação de todas essas variáveis, são diversas as versões existentes da tradução latina da obra de Isaac de Nínive. No estado atual do conhecimento da tradição latina, no entanto, não é possível precisar quais testemunhos se encaixam exatamente em cada categoria, seja porque não foi possível o acesso à cópia de todos os testemunhos, seja porque não há informação suficiente nos catálogos que os registram. Com base nos dados disponíveis até o momento, os 105 testemunhos localizados parecem distribuir-se em 54 integrais, 40 não integrais e 11 sem informação segura quanto à extensão.

No presente trabalho, apresenta-se uma edição paleográfica de nove dos testemunhos não integrais (a que se podem chamar genericamente de fragmenta latina). O critério de escolha desses testemunhos para serem editados aqui foi principalmente pragmático: trata-se de testemunhos a cuja cópia foi possível ter acesso e que estão dentre os mais curtos.

\section{NORMAS DE EDIÇÃO}

Serão aplicadas neste trabalho as normas de edição paleográfica propostas por Cambraia (2005b, p. 129-130), com algumas adaptações em função de se tratar de texto em latim, tal como procedeu Laranjeira (2018), e de haver limitação de espaço:

a) Caracteres alfabéticos: Transcrição como caracteres romanos redondos, reproduzindo-se as diferenças de módulo. Uniformização dos alógrafos contextuais segundo a forma mais moderna. Quando houver mais de um tipo de caractere no modelo (como, p. ex., capitulares), informa-se em nota. F duplo em início de período foi considerado como sendo uma única maiúscula.

b) Sinais abreviativos: Desenvolvimento de todos com base nas formas por extenso presentes no modelo, transcrevendo em itálico os caracteres acrescentados em substituição ao sinal abreviativo. Foram considerados sinais especiais os sinais abreviativos sobrescritos em forma de traço vertical com curva na parte superior (e não como $i$ sobrescrito) e o traço em forma de curva aberta para cima (e não como $u$ sobrescrito).

c) Diacríticos: Sem transcrição.

d) Sinais de pontuação: Transcrição fiel segundo as formas presentes no modelo. Por questões técnicas, casos de barra inclinada com ponto no centro foram transcritos como barra seguida de ponto. Após sinal abreviativo no final de abreviatura, é comum ocorrer ponto, elemento que não foi transcrito quando se considerou que fizesse parte do sistema abreviativo, e não do sistema de pontuação.

e) Caracteres de leitura duvidosa: Transcrição entre parênteses redondos simples ().

f) Caracteres riscados e apagados: Transcrição entre chaves duplas $\{\{\}\}$.

g) Caracteres nas entrelinhas: Transcrição, já no ponto do texto pertinente, entre parênteses uncinados duplos $<<>>$. 
h) Caracteres nas margens: Transcrição, no ponto do texto pertinente, entre parênteses uncinados simples seguidos de chave simples $\langle\{\}\rangle$. Informação em nota, quando a marginália não fizer parte do texto e estiver legível.

i) Separação vocabular (intra- e interlinear): Reprodução fiel da separação interlinear, mas normalização da separação intralinear segundo a tradição lexicográfica da língua latina. Não foi transcrito hífen marcando separação interlinear, sendo transcrito ou inserido quando há mudança de fólio.

j) Paragrafação: Reprodução fiel.

k) Inserções conjecturais: Inserção dos elementos por força do contexto entre parênteses uncinados simples $<>$ e por desgaste do suporte entre colchetes simples []. Variações linguísticas, sobretudo relacionadas à supressão de fonemas nasais, foram mantidas na transcrição.

1) Supressões conjecturais: Transcrição de erros que não sejam por repetição entre chaves simples \{\} .

m) Mudança de linha: Indicação com barra reta $\mid$.

n) Mudança de fólio, face e coluna: Informação no início da transcrição de cada face de fólio, em negrito e entre barras inclinadas: / /. Nos casos em que o texto não começa na primeira linha do fólio, indica-se o número da linha de início após a indicação da face do fólio.

o) Mudanças de punbo: Informação em nota.

p) Mudanças de tinta: Transcrição de texto originalmente em rubrica em negrito. Iniciais ornadas com cor diferente (vermelha ou amarela) foram representadas na transcrição com negrito. Nos casos de cópia de testemunho em preto e branco, a identificação de rubrica foi feita com base na diferença de tonalidade.

q) Qualquer outra particularidade: Informação em nota.

r) Indexação: Indicação da correspondência dos textos editados com a versão da Patrologia Graeca (PG) de Migne (1865) em nota, informando-se capítulo (c.), coluna (col.) e linha (1.).

Considerando que as descrições codicológicas dos testemunhos que serão editados aqui estão atualmente, na sua maioria, disponíveis on-line, serão apresentados apenas apontamentos codicológicos mínimos para cada testemunho.

\section{EDIÇÃO}

\subsection{Cód. XIV G 17, Biblioteca Nacional (Praga), ff. 14va-15rb}

Apontamentos codicológicos e paleográficos: Papel - s. XIV ( $2^{\mathrm{a}}$ met. $)-\mathrm{I}+207$ ff. num. $-20,5 \times 15$ - Proprietários: nota indicando o Mosteiro da Casa dos Cânones Regulares de Santo Egídio em Witignaw, i. é, Třeboň, datável do séc. XIV (margem superior do verso do plano anterior); ex-libris de Pedro Vok de Rosemberg datado de 1609 (verso do plano posterior); nota indicando a Biblioteca dos Cânones Regulares de Santo Agostinho de Třeboň datada de 1718 (margem superior do f. 2r), Biblioteca Nacional da República Tcheca - Origem: Mosteiro agostiniano de Třeboň (no sudoeste da República Tcheca) - Descrição completa: Truhlář (1906, p. 333-334) - 
Foliação original em romano convertida para a correspondente em arábico na transcrição - Há certa oscilação no uso de a bastardo e uncial, diferença que foi uniformizada em uma só forma de $a$ na transcrição.

Transcrição: /f. 14va32/ HJc ${ }^{2}$ ordo est sobrius et deo amabilis $\mid$ Non respicere oculis hinc inde / sed | semper ante se Non ociosa verba loqui sed tantum | neccessaria / Jndumentis vilibus contentum esse | ad neccessitatem corporis / et sic cibis ad sus|tentacionem corporis vti ut non castrimar|gie seruiatur et participare parum de omnibus | et non reprobare hoc et eligere hoc Nec imple|at ex ipsis ventrem Maior est enim om $n$ i | virtute discrecio Vinum propter infirmitatem aut $\mid$ debilitate $m$ non sumere / Non prescindas verbum | loquentis sicut indoctus sed respondeas sicut /f. 14vb/ prudens ${ }^{3}$ Tacitus esto vbicu $m q u e$ fueris $\mid$ invent $u s$ Minore $m$ te ipsum existima $e t$ ser $\mid$ uu $m$ fratrum tuorum Nec denudes coram | aliquo aliquid membrorum tuorum / Nec appro|pinques corpori alicuius preter neccessitatis | causam Nec corpori tuo permittas aliquem | approp $<<$ in $>>$ quare ut dixi nisi ex racionabili causa | Declina a fiducia mulierum sicut a mor|te Posside sobrium ordinem sompni | ne elongetur a te virtus que te custodit | Jn quocumque loco dormieris si possibile | est nullus te uideat Si venerit tibi | tussis sedenti in mensa verte faciem tuam | retro et sic tussica $\mathbf{C u m}$ sobrietate comede | et bibe sicut decet filios dei Ne exte $n \mid$ das manu $m$ tua $m$ ut accipias a conspectu | proximi quid inverecunde uel presumptuose | $\mathrm{Si}$ autem sederit tecum extraneus annue ei | semel . et bis ut comedat et ordinate | pone mensam / non turbulente sed honeste | Non denudans quid membrorum tuorum | Cum oscitas os tuum aperi / Retine sus |piria si potes Si intraueris cellam pre|ceptoris tui aut amici uel dissimllis | caue ne uideas aliquid ibi / Si vero co|actus non fueris hoc non facias quia qui in hijs est assidu $u$ alienus est a monastico | habitu et christo qui hunc donauit Ne res | picias loca vbi sunt uasa abscondita | celle amici tui $\mathbf{C u m}$ tranquillitate oscium | et claude silenter similiter proximi tui Et | non subito ad aliquem introeas sed pulsans | exterius et permissus ingredere Ne sis ve|lox in gressu tuo preter causam neccessariam | te compellente $m$ Esto om $n$ ibus obediens | in om $n$ i tempore preter quam ad auaros et ama|tores possessionum uel seculares hos | non requaris ut non fias opus dya|bolicum Mansuete cum omnibus tracta etcum | sobrietate et honestate omnes aspice Et | non impleas oculos tuos alicuius rei $\mid$ Ambulans in uia non preuenias ma|iore $m$ te $\mathbf{S i}$ autem tardauerit socius tuus /f. 15ra/ parum progrediens exspecta eum Qui enim | non facit sic insipiens est $\mathbf{Q} u a$ ndo socius | tuus loquitur obuiantibus exspecta eum Sanus | dicat infirmanti ante tempus faciamus neccessi|tatem $\mathbf{N e c}$ arguas aliquem in aliquo . sed | te ipsum in omnibus existima culpabi|le $m$ et debitore $m \mathbf{O}$ me opus vile iussus | cum humilitate facere non recuses $\mathbf{S i}$ coac|tus fueris ridere non appareant dentes | tui Si compulsus fueris loqui cum muliere | verte faciem tuam ne uideas eam et sic cum | ea loquere / A monialibus fuge sicut ab | igne et laqueo dyaboli et obuiacionem earum et | colloqucionem et uisionem ut non colorent cor $\mid$ tuum sordibus viciorum quamuis sint soro $\mid$ res tue secundum carne $m$ sicut $<<\mathrm{ab}>>$ extraneis te cus|todi A fiducia iuuenum et locucione | fuge sicut ab amicicia dyaboli Vnu $m$ habe | colloqutore $m$ timente $m$ d $e u \mathrm{~m}$ et se ipsum cus $\mid$ todientem Pauperem quide $m$ in thaber $\mid$ naculo suo $\{\{\mathrm{sed}\}\}<<e t>>$ diuite $m$ in misterijs dei $\mid$ ab omnibus absconde misteria tua opera|ciones et prelia Ne sedeas coram aliquo sine $\mid$ habitu tuo preter neccessitatem Cum sobrietate | ad neccessariam curam egredere sicut verecundans |

$2<\mathbf{H}>$ capitular rubricado.

${ }^{3} \mathrm{Na}$ margem superior desta coluna há texto que pertence à obra de Hugo de São Victor (Migne, 1854, col. 888, 1l. 17-18 e 25-28): <Jnfirma mundi elegit deus et ignorabilia et co<n $>$ tempcibilia | quoniam ipse qui diues est in gloria sua pauper factus est pro $\mid \mathrm{n}$ [obis] non diuicibus sed pauperibus dignatus est sociari>. 
custodiente te angelo et cum timore profi|ciscere / Melius est tibi comedere venenum | mortiferum quam cum muliere comedere quamuis | sit mater uel soror tua. Melius est habita|re cum dracone quam dormine cum aliquo | et cooperiri cum eo quamuis sit tibi frater secundum $\mid$ carnem Si dixerit tibi ambulanti in $\{\{\mathrm{vi} \mid \mathrm{a}\}\}$. maior itinere quis maior te / veni | ut psallamus noli esse inobediens ei | Si autem non dixerit / lingwa quidem ta|ce corde vero deum glorifica Ne resistas | alicui pro aliquo facto Nec certes nec me $n \mid$ ciaris nec iures per nomen dei tui $\mid$ despice te ipsum et alios non despicies $\mid$ Jniurias sustine et nemini iniuriam | feceris Melius est corporalia corrumpi cum | corpore quam dampnificari quid anime $\mathbf{J n}$ iu|dicio cum aliquo non introeas sed sustine | condempnatus incondepnabilis existens /f. 15rb/ Ne diligas anime tue aliquid seculare | sed subditus esto ducibus principibus | et a conuencione ipsorum abstine te ipsum Jpsorum | namque conuersacio est illaqueans negli|gentes in perdicione $\mathbf{O}$ gulam qui propriam | queris curare gulam Melius est tibi mittere | in ventre $m<\{$ tuu $m\}>$ carbones ignis quam frixu|ras ducum et principum Superfunde tibi | super om $n$ e oleum misericordie et esto obseruans | te ab omnibus A multiloquio te ipsum custo|di Jllud enim extigwit in corde mo|ciones intellectuales a deo pululantes | Fuge docmatizare cum prelatis ecclesie | aut cum alijs sicut a lloqucione audaci $\mid \mathbf{E t}$ in plateis iracundorum aut compugnan | cium ne transeas ut non impleatur cor | tuum furore et detur anime tue furoris | obscuritas $\mathbf{N e}$ habites cum superbo ut $\mid$ non sancti spiritus operacio auferatur ab anima | tua et efficiaris habitaculum omnium viciorum $\mid \mathbf{H}$ as deposiciones si senuaueris o homo | et custodieris te ipsum semper in meditacione | dei in veritate videbit anima tua in se | met ipsa anime christi et in seculum seculi non tenebrescet illi gloria in secula seculorum amen ${ }^{4}$ \{ \{Explicit dictum ysaac abbatis syrie | de informacione iuuenum ex ultimo capitulo | libri sui de xij sermonibus $\}\}^{5}:-\cdot:-$

\subsection{Cód. M I 159, Biblioteca Científica (Olomouc), ff. 20r-20v}

Apontamentos codicológicos e paleográficos: Papel - s. XV (último terço) - I + 248 + III ff. $-22 \times 15,5$ - Origem: Parcialmente oriundo de Litoměřice (no noroeste da República Tcheca) - Descrição completa: Boháček e Čáda (1994) - Foliação moderna em arábico - Os sublinhados no manuscrito, sempre em rubrica, foram registrados na transcrição - Alguns pontos e barras estão em rubrica, aspecto que não foi marcado com negrito na transcrição - Na margem externa do f. $20 \mathrm{v}$ há dois comentários que não puderam ser devidamente decodificados e, portanto, não foram transcritos.

Transcrição: /f. 20r20/ Tractatus beati Bernardi de directione vite Jncipit $\mid \underline{\mathbf{H}} \mathrm{J}_{\mathrm{c}^{6}}$ ordo est sobrius et deo amabilis non respicere oculis hinc inde . sed respicere | ante se . hoc est cogitaciones iactare in deum Et sic respicere. est . non ociosa verba | loqui . sed tantum neccessaria Jndumentis contentum esse ad neccessitatem corporis. et sic cibis $\mid$ ad suste $n$ tacionem corporis vti $\mathrm{n}\{e c\}$ on castrimargie seruiat $u \mathrm{r}$. Et participare de omnibus parum | et non reprobare et hoc eligere. nec impleat ex ipsis ventrem. Maior est enim omni virtute | discrecio. Vinum preter infirmitatem aut debilitatem non sum $<\mathrm{er}>\mathrm{e}$. Non prescindas verba loquentis vt $\mid$ indoctus . sed respondeas sicut prudens . Tacitus esto vbicumque fueris inuentus cum (opericet) / Minorem | te ipsum existima et seruu $m$ fratrum tuorum . nec denudes coram aliquo aliquid membrorum tuorum / I nec appropinques

\footnotetext{
${ }^{4}$ PG 86, c. LIII, coll. 883 (1. 20) - 886 (1. 9).

${ }^{5}$ Escrito por outro punho em letra gótica quadrada e riscado de vermelho.

$6<\mathbf{H}>$ capitular rubricado.
} 
corpori alicuius nisi propter neccessitatis causam . nec corpori tuo permittas aliquem appropinquare / vt dixi nisi ex racionabli causa / Declina a fiducia mulierum sicut a morte / posside | sobrium ordinem somni /. ne elonget $u$ r a te virtus que te custodit $\mathbf{J} \underline{\mathbf{n}}$

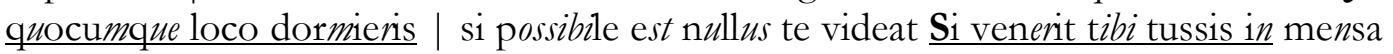
sedenti verte facie $m$ tua $m$ | retro et sic tussita $\mathrm{Cum}$ sobrietate comede et bibe sicut decet filios dei. $\mathbf{N e}$ exten|das manum tuam vt accipias in conspectu christi tui quid

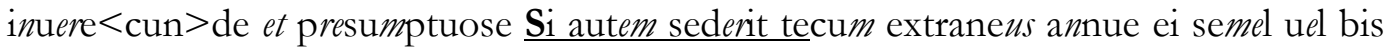
vt comedat et ordina te et pone | mensam non turbulente . sed honeste . non denudas aliquid membrorum tuorum Cum osci-/f. 20v/-tas os tuum aperi . retine suspiria si potes

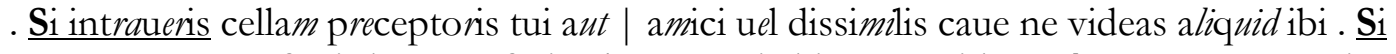
vero coactus non fueris hoc non facias | quia qui in hijs est assiduus alienus est a monastico habitu et christo qui hunc donauit. Non respicias | loca vbi sunt uasa reposta vel abscondita celle amici tui Et non subito aliquo | introeas . sed pulsans exterius et permissus ingredere ne sis velox in ingressu tuo / nisi $\mid$ propter causam neccessariam te compellentem Esto omnibus obediens in bono et omitte plus quam aua|ris Auaros uel amatores possessionum uel seculares hos non sequaris vt non fias | opus diaboli / Mansuete cum omnibus tracta et cum sobrietate et honeste omnes accipe Et $\mid$ non impleas oculos tuos alicuius re $\underline{\mathbf{A m b} u l a n s}$ in via non preuenias maiorem te |in dignitate $\underline{\mathbf{S i} \text { autem tardauerit }}$ socius tuus parum progrediens expecta illum Qui enim $\mid$ non sic $\{\{$ inspiciens\}\} est insipiens . cum socius tuus loquitur ab amantibus expecta eum $\mid \underline{\text { Sanus }\{\{\mathrm{t}\}\} \text { dicat }}$ infirmanti / ante tempus faciamus neccessitatem / nec arguas aliquem in aliquo sed te ipsum | in omnibus existima culpabilem et debitore $m$ Omne opus vtile iussus cum humilitate

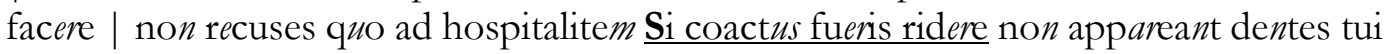
I Si compulsus fueris loqui cum muliere. verte faciem tuam ne videas eam et sic cum ea loquere | A monialibus fuge sicut ab igne et laqueo diaboh / et obuiacionem earum collocucionem et $\mid$ visionem vt non colorent cor tuum sordibus viciorum quamuis sint sorores tue secundum carne $m$ sicut ab | extraneis te custodi $\underline{\mathbf{A} \text { fiducia iuuenum et }}$

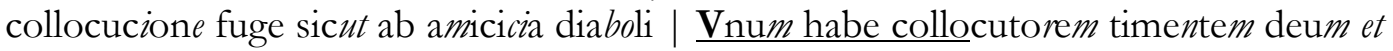
se ipsum custodientem / pauperem quidem in taberna|culo suo et diuitem in ministerijs dei Absconde ministeria tua operaciones et prelia ne se|deas coram aliquo sine habitu tuo

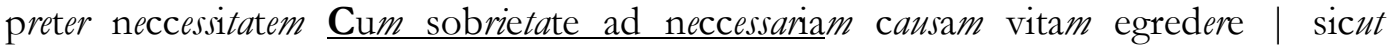
verecundus custodiente te angelo et cum timore proficere / Melius est tibi comedere venenum | mortiferum quam cum muliere comedere quamuis sit mulier vel soror tua / Melius est habitare cum | dracone quam cum aliquo <et $>$ cooperiri . cum $<$ eo $>$ quamuis

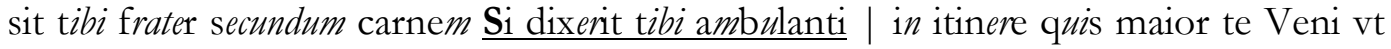

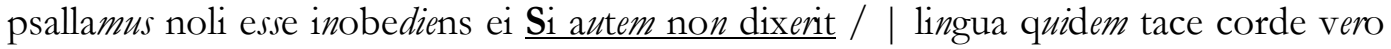
deum glorifica $(\underline{\mathbf{R}})$ es vires ${ }^{7}$ per nomen dei tui despice te ipsum | et alios non despicies Jniurians sustine et nemini iniuriam feceris / Melius est c <or $>$ poralia | corumpi cum corpore / quam damnificare quid anime . Jn iudicio cum aliquo non introeas sed sustine | condemnatus incondemnabllis christus / ne diligas aliquid anime tue seculare . sed subditus esto | ducibus et principibus / a conuencione ipsorum abstine te ipsum Jpsorum namque conuersacio est illaqueis / negligentes in predicacione / $\mathbf{O}$ gulose qui propriam queris curare gulam / Melius est mittere tibi | in ventrem tuum carbones ignis quam frixuras ducum et principum Superfunde tibi $\mid$ super omne oleum $\{\{\text { ole }\}\}^{8}$ misericordie et esto obseruans te ab omnibus / a multiloquio te ipsum custodi Jllud | enim extinguit in corde mociones intellectuales a deo per vllulantes Fuge dogmatisare cum | prelatis ecclesie aut cum alijs alloquio audaci et in plateis iracundorum aut compugnancium non $\mid$ transeas $\underline{\mathrm{vt}}$

${ }^{7}$ O copista parece não ter entendido o modelo: registrou como $(\boldsymbol{R})$ es vires o que deveria ser Nec iures.

8 O e está incompleto. 
non impleatur cor tuum furore et detur anime tue obscirutas / Ne habites $\mid$ cum superbo vt non spiritus sancti operacio auferatur ab anima tua / efficiaris habitaculum omnium virtutum / Has / deposiciones si seruaueris $\mathbf{O}$ homo si custodieris te ipsum in meditacione dei in veritate videbit anima | tua in semet ipsa lumine christi et in seculum seculi obtinebis restet illi gratia in secula seculorum amen ${ }^{9}$ | finis huius

\subsection{Cód. 996, Biblioteca Mazarina (Paris), ff. 163r-164v (ff. 176r-177v)}

Apontamentos codicológicos e paleográficos: Papel - a. 1516 - 6 + 244 ff. - 17,1 $\times$ 12,3 - Copista: Johannes Nicolay (alias Apchon) da Ordem Menor do Convento franciscano de Troyes (f. 244r e verso da capa final) - Descrição completa: Molinier (1885, t. I, p. 495-499) - Foliação original em romano e moderna a lápis em arábico (com 13 a mais de diferença): adotou-se a moderna na transcrição - Ao final da linha, costuma haver barra inclinada, mesmo quando há separação intravocabular, caso em que a barra não foi transcrita.

Transcrição: /f. 176r12 $/{ }^{10} \boldsymbol{q}^{11}$ Sequitur secundus tractatus a beato ysaac editus . | $\mathbf{H J} \mathrm{c}^{12}$ est ordo sobrius et deo amabilis Non respicere oc $u$ lis hinc $\mid$ et inde / sed semper ante se / non ociosa verba proferre / sed tantum | necessaria Jndumentis vilibus contentum esse ad necessitatem corporis / I et sic $\{\{i\}\}$ cibis ad sustentationem corporis vti / non castrimargie et parti|cipare parum de omnibus / et non hoc reprobare / et hoc eligere / ut / impleat ex ipsis ventrem suum Major est enim omni virtute discrecio . Vinum preter infirmitatem aut debilitatem non sumere Non pre|scidas verbum loquentis / sed sicut indoctus respondeas / sed sicut prudens | tacitus esto. Vbicumque inuentus fueris / minorem te ipsum estima / et ser uum fratrum tuorum . Ne denudes coram aliquo aliquod membrorum / tuorum / nec appropies corpori alicuius / preter necessitatis causam . I nec corpori tuo permittas aliquem appropinquare / nisi ut dixi causa | rationabili. Declina a fiducia sicut a morte Posside sobrium or|dinem sompni / ut ne elongetur a te virtus que te custodit Quocumque | loco dormieris / si possibile est / nullus te videat Sputum coram a|liquo ne proicias Si euenerit tibi tussis sedenti ad mensam / ver/te faciem tuam retro et sic tusse. Cum sobrietate comede et bibe / | sicut decet filios dei / nec extendas manum tuam ut accipias a cons $\mid$ pectu proximi tui quid inuerecunde uel presumptuose $\mathrm{Si}$ autem | sederit tecum extraneus / annue eum semel et bis ut comedat / et / ordinate pone mensam Non turbulente / sed ordinate sedeas et honeste / /f. 176v $/{ }^{13}$ non denudans quid membrorum tuorum Cum obsitas aperi os tuu $m$ ne / videaris / retinens enim aspirationes transiet. Si intraueris cella $m$ | preceptoris tui / aut amici tui / uel discipuli / caue ne videas ali|quid ibi Si vero coactus non fueris / hec non facias / quia qui | in hiis assiduus est / alienus est monastici habitus et christi | qui hunc donauit $\mathbf{N e}$ respicias loca / in quibus abscondita sunt ua / sa celle amici tui / cum tranquillitate aperi hostium proximi | tui / et claude similiter Non subito ad aliquem introeas / sed pul|sans exterius et permissus ingredere. Ne sis velox in gressu tuo / preter causam necessariam te compellentem Esto omnibus obe/diens / et in omni tempore / preter auaris aut amatoribus posses $\mid$ sionum / aut secularibus / hos non sequaris / ut non fias

\footnotetext{
${ }^{9}$ PG 86, c. LIII, coll. 883 (1. 20) - 886 (1. 9).

${ }^{10} \mathrm{Na}$ margem superior por punho diferente: $<$ \ monachorum . \ Folium . clxiij . $>$ (primeiro caldeirão em azul e segundo em rubrica). Refere-se ao texto precedente, intitulado Speculum Monachorum.

${ }^{11}$ Caldeirão em azul.

$12<\mathbf{H}>$ capitular rubricado.

${ }^{13} \mathrm{Na}$ margem superior por punho diferente: $<\boldsymbol{\mathbb { I }}$ De honesta uita . $>$ (caldeirão em rubrica).
} 
opus dia|bolicum Mansuete cum omnibus tracta / et cum sobrietate et hone/state omnes aspice / et ne impleas oculos tuos aspectu alicuius rei / | Ambulans in via / ne preuenias maiorem te / si autem tarda|uerit socius tuus / parum egrediens expecta eum / qui enim non $\mid$ sic facit / insipiens est Quando loquitur socius tuus obuiantibus | expecta eum Sanus dicat infirmanti / ante tempus faciamus ne | cessitatem $\mathbf{N e}$ arguas alique $m$ in aliquo delicto / sed te ipsum in om nibus / presumas culpabilem et delicti causam esse Opus vile cum omni | humilitate facere ne recuses $\mathbf{S i}$ coactus fueris ridere / non appare / ant dentes tui Compulsus loqui cum muliere / auerte faciem / tuam a visione eius / et sic cum ea loquere. A monialibus fuge / sicut ab igne / et ut laqueo diaboli fuge obuiationem earum / | et collocutionem / et uisionem / ut non colorent cor tuum sordibus viciorum . | quamuis sint sorores tue secundum carnem sicut ab extraneis te custodi . A fiducia juuenum et allocutione fuge sicut ab inimicicia diaboli | vnum habe collocutorem et conscium secretorum et timentem deum / et | se ipsum custodientem / pauperem quidem existentem in tabernaculo / suo / diuitem vero in ministeriis dei $\mathbf{A b}$ omnibus absconde ministe|ria tua / et tuas operationes et prelia . Ne sedeas coram aliquo | sine habitu tuo / preter necessitatem Cum sobrietate ad necessaria | tua egredere sicut verecundans / custodiente te angelo / et cum ti|more ${ }^{14}$ dei perfice Melius $<<$ est $>>$ tibi comedere venenum mortiferum / quam cum | muliere comedere / quamuis sit mater tua uel soror tua . Melius est / habitare cum dracone / quam dormire cum aliquo / et cooperiri cum eo / /f. 177r $/{ }^{15}$ quamuis sit tibi frater secundum carne $m \mathrm{Si}$ dixerit quis maior te / tibi a $m$ /bulanti in itinere / veni psallamus noli esse inobediens si autem non $\mid$ dixerit / lingua tua quidem tace / corde vero deum glorifica Ne resi|stas alicui pro aliquo / nec certes nec mentiaris / nec iures per | nomen dei tui. Despice te ipsum / ut alios non despicias Jniuriam su /stine / et aliis iniuriam non eroges Melius est corporalia corrumpi | cum corpore / quam dampnificare quid anime $\mathbf{J n}$ iudicio cum aliquo non / introeas / sed sustine condempnatus (in)dampnabilis existens $\mathbf{N e}$ dili gas anime tue quid seculare / sed subditus esto ducibus et principibus / | et a (con)junctione ipsorum abstine te ipsum Jpsa namque illaqueatione | illaqueas sunt negligentiores in perditione $\mathbf{O}$ gulose qui propriam | queris saturare gulam Melius est tibi mittere in ventrem tuum | carbones ignis / quam frixaturas ducum aut principu $m$ Superinfunde | tibi super om ne oleum misericordie / et esto observans te in om nibus . A multi|loquio te ipsum custodi Jllud enim extinguit in corde intentiones intellec|tuales a deo pullulantes Fuge dominari cum prelatis ecclesie / aut cum | aliis sicut a leone mordaci. Et in plateis iracundorum aut compugnan $\mid$ tium ne transeas / ut non impleatur cor tuum furore / et detur anime | tue erroris obscuritas $\mathbf{N e}$ habites cum superbo / ut non sancti spiritus / operatio auferatur ab anima tua / et efficiaris habitaculum omnium vicior $u m^{16} \mid \mathbf{Q}$ uam pulchra et laudabilis est dilectio proximi / non sollitudo eius | extrahat nullus a dilectione $\mathrm{dei}^{17} / \mathrm{cu} m$ requies et ociositas est per/ditio anime / et magis quam demones possunt nocere ${ }^{18}$ Visio secularium | confusionem facit anime renitenti eam propter opus dei / spiritualium fratrum | assidua locutio nocet Jtem secularium etiam sola visio exterior ope $\mid$ ratione $m$ corporalem impedit ${ }^{19} \mathrm{Ne}$ tristeris nec conturberis in cale $\mid$ factionibus corporis / post enim accipiet eas a te perfectio $\mathbf{N e}$ vincas

\footnotetext{
${ }^{14} \mathrm{Na}$ margem externa: $\langle$ Nota $>$.

${ }^{15} \mathrm{Na}$ margem superior por punho diferente: $<\boldsymbol{\Phi}$ religiosorum . \ Folium . clxiiij . $>$ (primeiro caldeirão em azul e segundo em rubrica).

16 PG 86, c. LIII, coll. 883 (1. 20) - 886 (1. 5).

${ }_{17}$ PG 86, c. LII, col. 881 (1l. 47-48).

18 PG 86, c. LII, col. 882 (11. 43-44).

19 PG 86, c. LII, col. 882 (1l. 2-6).
} 
| mortem / quia dominus te fecit super morte $m^{20}$. Has depositiones si | seruaueris o homo / et custodieris te ipsum in meditacione rei et / veritate / videbit anima tua in semet ipsa lumen christi / et in seculum non | erubescet Jpsi honor et gloria in secula seculorum Amen ${ }^{21}$. | | Explicit secundus tractatus a beato ysaac editus . | $\mathbf{~}^{22}$ Sequitur tertius tractatus eiusdem De honesta vita religiosorum. /f. 177v/ $/^{23}$ DEcet $^{24}$ enim monachum in omnibus esse formam vtilitatis videntibus | eum et ex multis virtutibus eius fulgentibus sicut radij | prospicientes inimici veritatis / et etiam inuiti confiteantur quod | sit spes christianis certa salutis / et tanquam ad refugium vndique concurrant | ad eum . ut cornu ecclesie exaltetur contra inimicos suos / et multi mo|ueantur ad $\{\{$ ve $\}\}$ virtutis zelum / et recedant a sec $u$ lo Jpseque fiat ve/nerabilis / ex pulchritudine conuersationis sue. Conversatio | etenim $\{\{$ monasticha $\}\}$ monastica / gloria est ecclesie ihesu christi . Decet | vtique monachum habere pulchros gestus / ex omni parte sui propter visio $\mid$ ne $m\{\{$ sublimiu $m\}\}$ visibiliu $m$ / et certissima $m$ priuatione $m$ rerum / omnimod(o) | carnis contemptum / altum jeiunium / constan $\{\tan \}$ tiam quietudinem / | temperantiam sensuum / visus custodiam / omnique vitiorum Jn rebus | huius seculi abstinentiam / breuitatem in verbis / in multorum recor|datione munditiam / cum discretione simplicitatem. Scire quod hec / vita superflua sit et inanis / et quod prope est illa vita spi | ritualis et vera Non ligare amiciciis et vnioni alicui hominum $\mid \mathbf{H}$ abere locum habitationis tranquillum / fugere homines / et indesin(a)nter | permanere in orationibus. Non habere ambitionem / nec gaudere / e $n c)$ eniis / nec ligare se ipsum huic vite Temptationes viriliter | sustinere / Alterari a mundanis affectibus / et interrogatione $m$ | rerum ipsarum non curare Continue meditari in regione ve|ritatis . $\mathbf{H}$ abere vultum pallidum et rugosum / lacrimari nocte dieque | Et plus hiis omnibus custodire propriam castitatem Esse mun $\mid$ dum ab ingluuie ventris / et a paruis et a magnis $^{25} \cdot \mid \mathbf{q}^{26}$ Explicit tertius tractatus de honesta vita.

\subsection{Cód. C 631, Biblioteca Universitária (Uppsala), ff. 333v-334r e 335v}

Apontamentos codicológicos e paleográficos: Papel e pergaminho - depois de 1416 - 355 ff. - $22 \times 15,5$ - Copista: Johannes Johannis (1404-1440), monge do Mosteiro de Vadstena, da Ordem de Santa Brígida - Descrição completa: AnderssonSchmitt, Hallberg e Hedlund (1993, p. 164-176) - Paginação original com elemento alfabético e algarismo romano e foliação moderna a lápis em arábico: adotou-se a moderna na transcrição - Há, entre os ff. 334v e 335r, cópia de parte do c. 14 do livro terceiro dos Diálogos de São Gregório (Migne, 1849, col. 244, 1. 31- col. 248, 1. 45), com relato histórico da vida de Isaac de Antioquia (ff. 334v e 335r27); um comentário de origem não identificada (f. 335r28-31); e parte do c. LVII da primeira parte da Vita Christi do Ludolfo da Saxônia (Saxonia, 1870, t. II, p. 521), apesar de constar na margem interna Augustus (f. 335r32-40) - O $n$ de amen apresenta forma diferenciada, provavelmente assinalando final de seção, mas foi uniformizado na transcrição - Dada a dificuldade de diferenciar ponto pertentence ao sistema de abreviação e ao de pontuação, mantiveram-se na transcrição todos os pontos.

\footnotetext{
${ }^{20}$ PG 86, c. LII, col. 883 (1l. 14-17).

21 PG 86, c. LIII, col. 886 (11. 5-9).

${ }^{22}$ Caldeirão em azul.

${ }^{23} \mathrm{Na}$ margem superior por punho diferente: $<\boldsymbol{\Phi}$ De honesta uita . $>$ (caldeirão em rubrica).

$24<\mathbf{D}>$ capitular rubricado.

${ }^{25}$ PG 86, c. XXIV, coll. 851 (1. 54) - 852 (1. 26).

${ }^{26}$ Caldeirão em azul.
} 
Transcrição: /f. 333v/ Jnformacio Nouiciorum et juuenum optima doctrina ${ }^{27}$ | $\mathrm{Hic}^{28}$ est ordo sobrius et deo amabilis . non respicere oculis hinc $\mid$ inde sed semper ante se. Non ociosa verba loqui . sed tantum neccessaria Jndu|mentis vilibus contentum esse ad neccessitatem corporis . Et sic cibis corporis | vti . ut no $n$ castrimargie senuiatur . et participare parum de omnibus et non repro|bare hoc et hoc eligere. nec impleat ex ipsis ventre $m$. Maior est enim . I omni virtute discrecio . Vinum preter infirmitate $m$ aut debilitate $m$ non sumere. Non $\mid$ prescindas verbum loquentis . et sicut indoct $u s$ respondeas . sed sicut prudens . | Tacitus esto vbicumque fueris inuentus. Minorem te $<<$ ipsum $>>$ existima . et seruum fratrum tuorum $\mid \mathbf{N e c}$ denudes coram aliquo . aliquid membrorum tuorum Nec appropinques corpori | alicuius preter neccessitatis causam . Nec corpori tuo permittas . aliquem appropinquare | vt dixi nisi ex racionabili causa. Declina a fiducia mulierum sicut a morte ${ }^{29}$. | Posside sobrium ordinem sompni . Ne elongetur . a te virtus que te custodit $\mathbf{J n} \mid$ quocumque loco dormieris si possibile est. nullus te videat $\mathbf{S}$ i venerit tibi tussis $\mid$ sedenti in mensa . verte faciem tuam retro et sic tussias Ne extendas man $u \mathrm{~m}^{30}$ | tuam ut accipias a conspectu proximi tui . quid inuerecunde vel presumptuose . | Si autem sederit tecum extraneus annue ei semel et bis ut comedat. Et ordinate | pone mensam. non turbulente sed honeste . non denudans quid membrorum tuorum . | Cum oscitas os tuum operi Retine suspiria si potes Si intraueris cellam . | preceptoris tui aut amici vel . dissimilis . caue ne videas aliquid ibi $\mathrm{Si} \mid$ vero coactus non fueris hoc non facias . quia qui in hiis est assiduus alienus est. | a monastico habitu et christo hunc qui donauit $\mathbf{N e}$ respicias loca . vbi sunt $\mid$ vasa abscondita celle amici tui . $\mathbf{C u} m$ tranquillitate aperi hostium et | claude silenter. simliter proximi tui . et non subito ad aliquem . introeas sed pul|sans exterius et permissus. ingredere. Ne sis velox in gressu tuo preter causam neccessariam | te compellentem. Esto om nibus obediens in omni opere . preter quam ad auaros . vel | amatores possessionum vel seculares hos non sequaris ut non fias opus | dyabolicum Mansuete tamen tracta . cum et sobrietate et honestate omnes | aspice . et non impleas oc $u$ los tuos aspectu alicuius rei. Ambulans in . | via non prevenias maiorem Si autem tardauerit socius tuus parum progrediens ex / specta eum qui enim non facit sic insipiens est. $\mathbf{N} e c$ arguas aliquem in aliquo . | sed te ipsum in omnibus existima culpabilem et debitorem. Omne opus vile iussus $\mid$ cum omni humilitate . facere non recuses. Si tactus fueris ridere non appareant $\mid$ dentes tui /. Si compulsus fueris loqui . cum muliere verte faciem tuam . ne vide $\mid \mathrm{as}^{31}$ eam . et sic cum ea loquere /. A monialibus fuge sicut ab igne et laqueo | dyaboli . et obuiacionem earum et colloqucionem . et visione $m$. vt non colorent | cor tuum. sordibus viciorum Quamuis sint sorores tue secund $u \mathrm{~m}$ carnem. sicut $\mid \mathrm{ab}$ extraneis te custodi ./ A fiducia juuenum loqucione . fuge sicud ab amicicia | dyaboli . Vnum habe colloqutore $m$. et consiliatore $m$ timente $m$ deum et se ipsum custo|diente $m$. pauperem quide $m$ existente $m$ in tabernac $u$ lo suo . et diuite $m$ i $n$ misteriis dei . /f. 334r/ Ab om nibus absconde misteria tua . operaciones et prelia. Ne sedeas coram aliquo . I sine habitu tuo preter neccessitatem. Cum sobrietate ad neccessariam curam egredere | sicut verecundans custodiente te angelo et cum timore proficiscere Melius est | venenum mortiferum quam cum muliere comedere . quamuis sit mater vel soror tua . | Melius est habitare cum dracone quam dormire cum aliquo et cooperiri cum eo quamuis | sit tibi frater . secundum carne $m$ Si dixerit tibi ambulanti in itinere quis maior Veni ut psal|lamus noli esse inobediens ei. Si autem non dixerit. lingua quidem tace . corde vero | deum

${ }^{27} \mathrm{Na}$ margem superior: < Jeiunes . vigiles . (s)icies sic rerc(?)ta cures $>$.

$28<\mathbf{H}>$ capitular rubricado.

${ }^{29} \mathrm{Na}$ margem interna: $<$ nota $>$.

${ }^{30} \mathrm{Na}$ margem externa: $<$ Nota $>$.

${ }^{31} \mathrm{Na}$ margem externa: $<$ Nota $>$. 
glorifica $\mathrm{Ne}$ resistas alicui pro aliquo facto nec certes . non menciaris nec | jures per nomen dei tui. Despice te ipsum et alios non despicias Jnjurias | sustine et nemini iniuriam facias Melius est corporalia cum corrumpi corpore . | quam dampnificare quid anime . Jn iudicio cum aliquo ne introeas sustine condempnatus . | incondempnabilis existens $\mathbf{N e}$ diligas anime tue aliquid seculare sed subditus esto ducibus | et principibus et a conuencione ipsorum abstine te ipsum Jpsorum namque conuersacio est. illaqueans | negligentes in perdicione / O gulose qui propriam queris curare gulam . melius est tibi ${ }^{32}$ mittere in ventrem tuu $m$ carbones ignis quam frixuras ducum et principum. Super $\mid$ funde tibi super omne oleum misericordie . et esto obseruans te ab omnibus / a multiloquio te ipsum . | custodi . illud enim extinguit in corde mociones intellectuales a deo pullulantes - Fuge docmatizare . cum prelatis ecclesie . aut cum aliis sicud . a loqucione audaci Et in | plateis iracundorum aut compugnancium ne transeas vt non impleatur cor tuum furore. I et detur anime tue furoris obscuritas. Ne habitas cum superbo vt non sancti spiritus operacio . | auferatur ab anima tua . et efficiaris habitaculum omnium viciorum / Has deposiciones si ser|uaueris o homo et custodieris te ipsum semper in meditacione. dei in veritate . videbit anima tua . | in semet ipsa lumen christi . et in seculum seculi non tenebrescet . christi gloria . in secula seculorum $\mathbf{A m e n}^{33} \mid \mathbf{N u n q u a m}{ }^{34}$ turpis aut lasciuus sermo de ore monachi egrediatur . in hiis enim signis | libidinosus . animus ostenditur . et per exteriorem hominem interioris hominis vicia | demonstrantur. Monachus non desiderat verborum frequenciam que de singularitate | censet $u$ r. Monachus sit vigil sensibus semper. nec vanis cogitacionibus polluatur. | Amet scienciam scripturarum et carnis scienciam non amabit Monachus qui christum | desiderat nil aliud dignatur respicere . sed per paradisum variarum scripturarum | poma decerpit . hiis vtitur deliciis . harum fruitur amplexu Monachus | habeat columbe simplicitatem. nec cuiquam machinetur dolum. Vita hominis sapientis . est. | meditacio mortis Tunc quid se monachum judicet cum se minimum estimauerit | cunctis 9 Pallor enim cum humilitate . et macies in facie decus est monachi. $\mathrm{Si}^{35} \mid$ potueris iniuriari . et affici contumeliis et portare et tacere magna est hec | res super omnia alia estiens mandata. Monachus qui in terris possessiones | querit monachus non est. qui secund $u \mathrm{~m}$ deum est. sapiens est. et beatus est. beata communio | diuinitatis et cogregacio virtutis et boni operis $A m e n^{36}$. /f. 335v/ Jmpropera ${ }^{37}$ tibi o frater semper dicens / $\mathbf{O}$ anima misera. dissolucio tua a corpore appropin|quauit quare delectaris in hiis que debes hodie derelinquere et a quorum aspectu pri|uaberis in eternum./ Attende que sunt ante te et cogita que operata es qualia sunt . I Et in quibus conuersata es omnibus diebus vite tue Seu quis laborem operacionis | tue recepit . Et quem in pugna tua letificasti . vt exeat in occursu tuo tempore . | exitus tui . Quem eciam delectasti in cursu tuo ut in portu eius quiescas . Cuius gratia . | laborando te afflixisti ut peruenias ad eum cum gaudio . Quem acquisiuisti | pro amico in futuro . ut in egressu tuo excipiat te. in cuius agro operata es . I Et quis debet tibi mercedem soluere . in occasu solis recessus . tui. Tu suscitare a temet | ipsa . o anima et vide / $\mathbf{Q}$ uod si pertransisti agrum fructificantem. Jn amaritudinem | suis cultoribus clama et vocifera in gemitu et anxietate ${ }^{38}$ que super sacrificia . | et holocausta placant dominum deum tuum

32 Na margem externa: $\langle$ Nota $>$.

${ }^{33}$ PG 86, c. LIII, coll. 883 (1. 20) - 886 (1. 9).

$34<\mathbf{N}>$ capitular rubricado.

${ }^{35} \mathrm{Na}$ margem externa: $\langle$ Nota $\rangle$.

36 Trecho ausente da PG 86, c. LIII, col. 886 (1. 9): trata-se de adição composta de frases de origem variada presente em diversos outros testemunhos. Cf. a identificação da origem de cada frase em Cambraia (2018, p. 116-118).

$37<\mathrm{J}>$ capitular rubricado.

${ }^{38}$ Há um sinal abreviativo para sequência com $r$ sobre esta palavra. 
. Producat os tuu $m$ dolorosas voces | quibus sancti angeli del $(e \operatorname{ctant} u) \mathrm{r}$ tinge genas tuas lacrimis vt super te spiritus. | sanctus requiescat. Et abluat te a sordibus malicie tue. Fac tibi propicium per | lacrimas . domin $u$ m ut ad te veniat / Jnuoca Mariam et martham vt luctuo| sas voces te doceant. clama ad domin $u \mathrm{~m}^{39}$. \{\{hanc perutilem oracionem $\left.\}\right\}$ legendo $^{40} \mid \mathbf{D O m i n e}^{41}$ qui super lazarum plorasti. Et super eum . compassionis lacrimas $/<<$ ef $>>$ fudisti $\mid$ suscipe lacrimas amaritudinis anime mee. Passio $n$ ibus tuis passiones meas sana. Vulnerbbus tuis medere . vulnera mea . Sanguine tuo sanguinem meum . I emunda . Et contempera corpori meo . viuifici corporis tui ordinem. Fel quod $\mid$ ab inimicis potatus es . dulce $m$ reddat animam meam ab amaritudine quam mibi | inimicus aduersarius propinat Corpus tuum . quod in ligno crucis extensum est. extollat $\mid$ ad te mentem meam. que a demonibus est inferius tracta . Caput tuum quod in crucis patibulo | reclinasti . erigat capud meum . ab inimicis colaphizatum Confixe clauis sanctis|sime manus tue . subleue $n$ t me ad te a confusione perdicionis depressi(one) sicut | os tuum sanctissimum repromisit. Facies tua que recepit alapas et consputaciones a $\mid$ maledictis . Clarificet facie $m$ meam iniquitatibus sordidatam /. Anima tua quam . | tradidisti patri tuo existens in cruce. deducat me ad te in gratia tua. Non habeo . I cor dolens ad requirendum te. Non habeo penitenciam . nec compunccionem que reducunt filios | ad suam hereditate $m$. Non habeo domine lacrimas deprecabiles Obtenebratus est. | animus meus nec potest ad te respicere in dolore. Aruit cor meum a multitudine. I temptacionum . $\mathbf{N} e c$ potest calefieri lacrimis tue dileccionis $\mathbf{S} e d$ o jhesu christe domine. I thesaure beatorum tribue mibi penitenciam perfectam /. cor dolens /. vt exeam pleno animo . I ad querendum te . nam sine te omni bono alienabor. Da mibi ergo christe gratiam tuam . I $\mathbf{P}$ ater qui te produxit. de sinu tuo eternaliter sine tempore. innouet in me formas ymaginis | tue . dereliqui te . non me derelinquas Exiui a te . exi ad requirendum me et introduc | in pascua tua. Et connumera me ouibus electi ouilis tui . et nutrias me cum eis $\mid$ in pratis diuinorum secretorum tuorum . quorum est habitaculum cor mundatum . et in ipso videtur | splendor reuelacionum tuarum que sunt consolacio et refrigerium eorum qui laborauerunt pro te in $\mid \mathrm{t} r \mathrm{~b} u \mathrm{lacio} n \mathrm{ib} u s$ et in omnibus afflictionibus qubus digni constituamur . gratia et pietate saluatoris | nostri nunc et in futuro seculo Amen ${ }^{42}$

\subsection{Cód. A XI 72, Biblioteca Universitária (Basileia), ff. 20v-22r, 35v e 55v}

Apontamentos codicológicos e paleográficos: Papel e pergaminho - s. XV - 184 ff. $-14,5 \times 10,5$ - Proprietário anterior: Mosteiro dos Cartuxos da Basileia - Descrição completa: Binz (1907, p. 353-361) - Foliação moderna a lápis em arábico.

Transcrição: /f. 20v15/ Oratio abbatis ysaac ${ }^{43} \mathbf{D}_{\text {omine }}{ }^{44}$ qui super | lazarum plorasti . et super eum lacrimas tue compassionis efudisti . suscipe lacrimas | amaritudinis mee. passionibus tuis passiones /f. 21r/ meas sana. wlneribus tuis medere / wlnera mea . sanguine tuo sanguine $m \mid$ meum emunda . et contempera corpori $\mid$ meo viuifici corporis tui odore $m: \mid$ Fel quo ab inimicis potatus $<<$ es $>>$ dulce $m \mid$ reddat animam mea $m$ ab amaritudine quam | mibi inimicus aduersarius meus propinauit : | Corpus tuum quod in crucis patibulo extensum est $\mid$ extollat ad te mentem meam que a de $\mid$ monibus est inferius

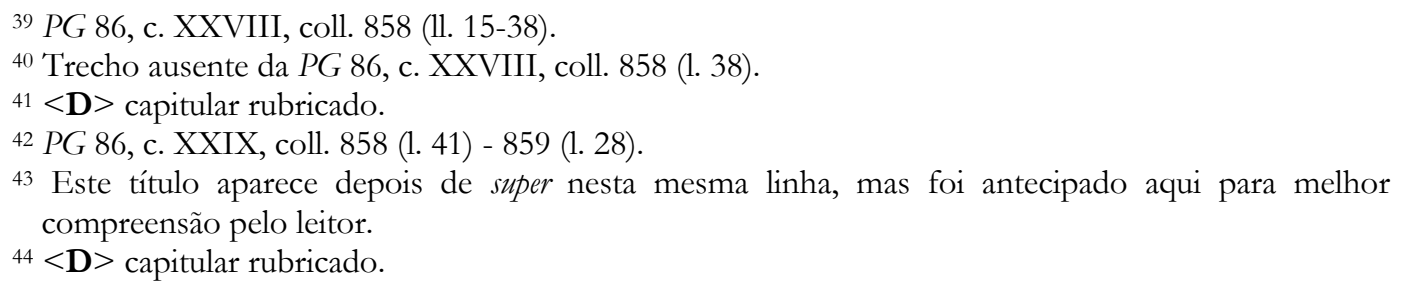


tracta : Caput tuu $m \mid$ quod in crucis patibulo reclinasti . erigat $\mid$ caput meum ab inimicis colaphizatum: | Crucifixe $\{\{\operatorname{man} u s\}\}$ clauis sanctissime $\mid$ manus tue subleuent me ad te. de | confusione perdicionis . sicut os tuum sanctissimum | repromisit: Facies tua que alapas rece|pit et consputaciones a maledictis . clari|ficet facie $m$ meam iniquitatibus sordidata $m: \mid$ Anima tua quam tradidisti patri tuo in cruce /f. 21v/ existens deducat me ad te in gloriam tuam | Ach mi domine ihesu christe . non habeo cor dolens | ad querendum te : non habeo penitenciam neque compunc | cionem que reducunt filios ad suam patriam et hereditatem /: non habeo domine lacrimas | deprecabiles . obtenebratus est in secularibus | animus meus. nec potest ad te respicere : in | dolore aruit cor meum a multitudine temptationum | : nec potest calefieri lacrimis tue dulcedinis | Sed o ihesu thesaure bonorum . tribue mibi | cor dolens . penitenciam ${ }^{45}$ perfectam . ut ex eam | pleno animo ad querendum te nam sine omni bono | alienabor /: Da mibi ergo ihesu christe gratiam tuam . | pater qui te produxit de sinu suo eternaliter sine | tempore innouet in me lumen ymaginis tue . | Dereliqui te non me derelinquas . exiui a te | exi ad querendum me . et introduc me in | pascua tua . et connu $<\mathrm{m}>$ era me ouibus /f. 22r/ electis ouilis tui /. et nutrias me cum eis | in partis diuiciarum secretorum /. quorum est | habitaculum cor mundatum /. et in ipso | videtur splendor reuelacionum tuarum . | que sunt consolacio et refrigerium eorum qui labo|rauerunt pro te in tribulacionibus /. et omnimodum | affliccionibus quibus digni constituamur gratia | et pietate saluatoris nostri $\mathrm{n} u n \mathrm{c}$ et in futuro | seculo amen ${ }^{46} / \mathbf{f} .35 \mathrm{v} 20 /$ [ab]bbas ysaac/ $\mathrm{Si} \mathrm{n}(o n)$ custodieris linguam $\mid$ tua $^{47}$ nunquam exilib(es) tenebras ${ }^{48} / \mathbf{f} .55 \mathrm{v} /\{\{$ Ex tractatu abbatis ysaac de vigilijs $\}\}$ | Noli putare o homo quod inter omnes operaciones monachorum $\mid \mathrm{si}<<\mathrm{t}>>$ alia quamlibet conuersacio maior vigilijs noct $u$ rnis $\mid$ Jn veritate fratres . si non fiat religioso dispersio et $\mid \mathrm{t} u \mathrm{rbacio}$ in carnalıbus rebus et in sollicitudine temporalium . sed cauerit $\mid$ sibi a mundo et custodierit se ipsum vigilijs . mens ei $u s \mid$ quasi cum alis in breui tempore uolat . et exaltatur in dileccione dei $\mid$ et cito peruenit ad gloria ${ }^{49}$. De vigilijs $\mid$ Monachum perseuerante $m$ in vigilijs cum mentis discrecione | ne respicias illu $m$ sic $u t$ fer $<\mathrm{u}>$ ente $m$ carne $m$. hoc vtique an | gelici ordinis opus est. non humanum $\mathbf{d} \boldsymbol{e}$ eodem | Jmpossibile est autem quod illos qui semper in huiusmodi continencia conuersantur | dimittat deus sine magnis donis . propter eorum ieiunium et | vigilanciam cordis ${ }^{50}$. de eodem | Ego uero puto impossibile esse quando ille qui cum sciencia et discrecione | preelegit sibi laborem istu $m$ magnum atque dininum . et arbi|tratus est ei $u s$ portare grauamen . et studiose laborat | in hac gloriosa parte quam elegit . et in die sibi cauet a | turbacione locucionum et sollicitudine pugnarum quod fiat nudus et | vacuus admirabili fructificacione magne dileccionis que | colligi prestolatur ab ipso ${ }^{51} \mid$ Ego quoque dico quod si corpus fessum fuerit propter infirmitatem suam | ut ieiunare non possit /. potest solis vigilijs mens acquir[ere] | statum anime . et intellectum prestare cordi ./ virtutem spiritualem | addiscat dummodo non fiat sibi exterminacio a di|latacione dininarum causarum ${ }^{52}$

${ }^{45}$ Há um sinal abreviativo para sequência com $r$ sobre o final desta palavra.

46 PG 86, c. XXIX, coll. 858 (1. 41) - 859 (1. 28).

${ }^{47}$ PG 86, c. LII, col. 882 (1. 56).

48 PG 86, c. LII, col. 883 (1. 3).

49 PG 86, c. XXXI, coll. 860 (1. 52) - 861 (1. 4).

${ }^{50}$ PG 86, c. XXXI, col. 861 (11. 6-12).

51 PG 86, c. XXXI, col. 861 (1l. 17-25).

52 PG 86, c. XXXI, col. 862 (11. 18-23). 


\subsection{Cód. A X 102, Biblioteca Universitária (Basileia), ff. 31v-32r}

Apontamentos codicológicos e paleográficos: Papel e pergaminho $-\mathrm{s}$. XV ( $2^{\mathrm{a}}$ met.) - 166 ff. - 14,5 × 10,5 - Copista: Martin Ströulin - Proprietário anterior: Mosteiro dos Cartuxos da Basileia - Descrição completa: Binz (p. 1-15) ${ }^{53}$ - Foliação moderna a lápis em arábico.

Transcrição: /f. 32r2/ \ Ex libello abbatis ysaac syrie // Qubus mund us est | mortuus . hij sustinent aduersitates gaude $n \operatorname{ter}^{54}$. | quibus vero mu $n \mathrm{~d} u s$ viuit . hij nequeunt iniuriam sustinere | sed a vana gloria moti ira turbantur . seu eciam a tristicia | occupantur. O quam difficile est ut acquiratur hec virtus. et | quantam gloriam obtinet apud deum ${ }^{55}$. Si potueris iniuriari | et affici contumelijs et portare et tacere magnis est hec res | super omnia alia efferens mandata ${ }^{56}$. Jniuriam sustine . | et nemini iniuriam feceris ${ }^{57}$. // Jde $m$. Beatus qui nouit hoc | et manet in solitudine . nec fluctuat in multitudine | operum. sed omnes corporales operaciones in laborem oracionis con|uertit . et credit quod quandiu operat $u$ r cum deo . et habeat sol| licitudinem in ipso die noctuque $\{\{\mathrm{d}\}\}$ non deficiet ei quicquam | de neccessarijs vsibus quemadmodu $m^{58}$ non cessat tempore ab opere | pro eodem. Si quis autem hoc non sustinuerit in solitudine | sancto opere iam instet. Operetur vtens quide $m$ eo tanquam | adiutore non tamen auide propter lucrum. // Nam istud | positum est infirmis . quia perfectioribus turbamentum | existit. Pauperibus enim et pigris patres exposuerunt | ut operentur . et non sicut rem neccessariam existente $m^{59}$. Hic est | verus $\bmod u s$ et cito perueniendi ad quiete $m$ mentis si bene $\mid$ intellexeris et tibi non peperteris ${ }^{60}$. donec moriatur exterior | homo a rebus mundi . non solum a peccato . sed ab om $n$ i cor|porali operacione. Similiter interior homo a prauis cogitacioni|bus . et infirmetur motus corporis naturalis ut non moueat $u \mathrm{r} / \mathrm{f} . \mathbf{3 2 \mathrm { v }} /$ in corde dulcedine peccatorum . non mouebitur ab homine | dulcedo spiritus sancti ${ }^{61}$. et quousque a corde suo sollicitudinem secularium | preter neccessarium vsum nature . ac dimictat dominum curare de | ipsis . spiritualis ebrietas in ipso non mouebit $u \mathrm{r}^{62}$.

\subsection{Cód. A XI 71, Biblioteca Universitária (Basileia), ff. 158r}

Apontamentos codicológicos e paleográficos: Papel e pergaminho - s. XV - 228 ff. - 14,5 × 10,5 - Proprietário anterior: Mosteiro dos Cartuxos da Basileia - Foliação moderna a lápis em arábico - Descrição completa: Binz (1907, p. 343-353).

Transcrição: /f. 158r13/ I Abbas ysaac sirie Nam quando virtus | spiritus superuenit virtuti anime que corroboratur per ipsam |. tunc pro lege scripturarum . mandata spiritus vadicantur | et a sensibili materia auxilio nullo eget. Quan|diu enim cor a materialibus

\footnotetext{
53 A descrição deste testemunho, realizada por Binz em data não informada, nunca foi publicada, mas uma cópia dessa descrição foi gentilmente cedida pelo setor de manuscritos da Biblioteca Universitária da Basileia.

54 PG 86, c. XIII, col. 828 (11. 2-3).

55 PG 86, c. XIII, col. 828 (1l. 6-10).

56 Trecho ausente da PG 86, c. LIII, col. 886 (1. 9): trata-se de adição extraída de conjunto de frases de origem variada presente em diversos outros testemunhos (Cambraia, 2018, p. 116-118).

57 PG 86, c. LIII, col. 884 (11. 49-50).

58 Sinal abreviativo para sequência com $a$ riscado sobre o $q$.

59 PG 86, c. X, col. 819 (1l. 32-44).

60 Trecho ausente da PG 86, c. X, col. 819 (1. 44): trata-se de adição também presente no cód. 1838 da Biblioteca da Abadia de Melk (f. 203r16-18) (Cambraia; Laranjeira, 2010, p. 25).

${ }^{61}$ PG 86, c. X, col. 820 (1l. 25-31).

62 PG 86, c. X, col. 820 (1l. 34-38).
} 
instruitur . doctrinam nimirum | error et obliuio comitantur . Cum uero doctrina spiritus | adest. tunc memoria custodit $u$ r illesa ${ }^{63}$

\subsection{Cód. GB $8^{\circ}$ 76, Arquivo Histórico da Cidade (Colônia), ff. 64r-64v, 67v, 69r- $69 \mathrm{v}$ e $70 \mathrm{r}-70 \mathrm{v}^{64}$}

Apontamentos codicológicos e paleográficos: Papel e pergaminho - s. XV (1 $1^{\mathrm{a}}$ met.) - 187 ff. - 14,5 × 10,5 - Origem do caderno com a obra de Isaac: Zwolle - Proprietário anterior: Frades da Ordem da Santa Cruz de Colônia - Descrição completa: Vennebusch (1983, p. 69-76) - Foliação original em romano e moderna a lápis em arábico: adotou-se a moderna na transcrição - A cópia consultada não permite diferenciar com clareza letras rubricadas, por isso não se registrou essa característica na transcrição - O punho dos ff. $67 \mathrm{v}$ e $69 \mathrm{r}-70 \mathrm{v}$ tem a particularidade de fazer o elemento superior do sinal de dois pontos em forma curva, resultando na semelhança deste sinal com a forma de um ponto e vírgula invertido; além disso, termina o traço de $t$ em posição final com barra inclinada para a esquerda, mas não se trata de sinal de pontuação.

Transcrição: /f. 64r/ De humilitate | TE ${ }^{65}$ ipsum paruipende in omnibus aput omnes homines : et exal| taberis super principes huius mundi Preveni omnes $\mid \mathrm{i} n c l i n a\{\{\mathrm{n}\}\}$ cione a salutacione tua : et honoraberis | super illos quj offerunt munera auri sophir Vilipende | te ipsum et videbis gratiam dei in temet ipso Nam vbicumque | humilitas nascitur : ibi oritur gloria dei Si laboraueris ma|nifeste vilipendi ab hominibus : Faciet te deus glorificari | Si habes humilitate $m$ in corde tuo : ostendet tibi deus gloriam | suam in corde tuo Esto contentus in magnitudine tua et $\mid$ magnus in paruitate tua Studeas despici et $\{\{$ honoraberis $\}\} \mid$ repleberis honore diuino Ne queras honorari cum interius | vlceribus plenus sis . contempne honore $m$ vt honoreris . ne di|ligas illu $m$ vt dedecus non incurras Quj currit post ho|nore $m$ honor fugit ante ipsum . et quj fugit illu $m$ perseque $\mid \mathrm{t} u \mathrm{r}$ ab ipso . et de illius humilitate fiet omnibus hominibus predicacio | Si despicis te ipsum ne honoreris deus te diuulgabit | Si vero propter veritatem contempseris temet ipsum precipiet | deus creaturis suis omnibus vt te laudent : et aperient | ante conspectum tuum ostium glorie creatoris sui et commendabit | te . quia secund $u$ m ymaginem et similitudinem eius existis : Homi|nem virtutibus fulgentem . hominibus vero contemptibilem appare $n \mid$ te $m$. et vita quidem splendente $m$. sciencia quoque preclarum . humilem vero | spiritu quis vidit Beatus quj humiliat se in omnibus quia ex|altabitur Nam quj propter deum paruipendit et humiliat semet | ipsum glorjficabit a deo Et quj propter deum exurit et $\mid$ sitit deus illum bonis suis inebriat Et qui propter eu $m$ fit | nud $u s$. stola incorrupcionis et glorie induetur ab ipso : et qui | pauper efficitur propter eum veris ipsius diuicijs consolabitur Te|met ipsum despici propter deum . et multiplicabitur tibi gloria | te penitus ignorante Jn tota vita tua temet ipsum reputa | peccatorem vt semper iustificeris : Fias que ydiota in sapiencia $\mid$ tua : nec apparere te facias $\{\{\mathrm{f}\}\}$ sapientem ydiota ex-/f. 64v/istens Nam vbi exaltat humilitas inutilem et indoctum $\mid$ quantus est ille quj fit materia veneracionis magnitud $i \mid$ nis et honoris Fuge vanam gloriam et glorificabe| ris . et timeto supenbiam et magnificaberis Non est | enim distributa filijs hominum vana gloria : neque

\footnotetext{
${ }^{63}$ PG 86, c. XVII, col. 834 (11. 25-32).

${ }^{64}$ Consulta através de fac-símile digital em preto e branco disponibilizado no Arquivo Histórico da Cidade (Colônia).

$65<\mathrm{T}>$ capitular.
} 
na|to mulierum elacio ${ }^{66}$ /f. 67v11/ \ Nota ${ }^{67}$ tres sunt modi per quos omnis anima racionalis deo potest appropinquare: | scilicet per feruorem fidei . uel per timorem . uel per dei disciplinam . Nullus enim potest appropinquare $\{\{$ deo $\}\}$ caritati dei : nisi precesserit | vnus de eius modi tribus modis. Sicut / ab ingluuie mentis | nascitur turbacio cogitacionum : ita et a multiloquio et immode | rantia locucionum ignorantia et mentis excessus Temporalium | rerum sollicitudo turbat animam $<<:>>$ et fermentacio que fit ex ipsis | mentem corrumpit et extrahit a quiete ${ }^{68}$ Jtem idem Corporalis | labor sine mentis mundicia . sicut sterilis nutrix est et $\mid$ vbera sicca : quia sciencie $\{\{\mathrm{s}\}\}$ dei appropinquare non potest . Et sic | quidam corpus laboriosum faciunt : sed nichil acquirunt. I Sicut qui seminat super spinas nichil metere potest : ita | qui odio et cupiditate destruit . non potest aliquid | adipisci (:) sed ex multis vigilijs et occupacione rerum infir| mat $u$ r in lectio suo ${ }^{69}$ :- - Jtem idem Esto omnibus obediens | in omni tempore preter auaris aut amatoribus passionum aut secularibus | hos non sequaris ut non fiat opus dyabolicum ${ }^{70}$. - /f. 69r21/ Que sunt temptaciones quibus anima proficit ${ }^{71}$ TEmptaciones $^{72}$ que fiunt a virga spirituali ad pro fectum et augmentum anime in quibus exercitatur | et probatur atque mundatur sunt iste . Pigricia . /f. 69v/ grauitas corporis . laxacio membrorum . accidia . I confusio mentis . dolores corporis . excisio spei $\mid$ ad horam. obtenebracio cogitacionum $m$. defectus | humani auxilij ad horam. egestas corporalis us $u^{73}$. /f. 70r3/ $\mid \mathrm{Ex}^{74}$ istis temptacionibus acquirit homo animam soli| tariam et sui proteccionem et humilitatem et cor contritum et ex hijs et ceteris alijs probatur quis venire ad | desiderium creatoris Hec enim dispensator ordinat | iuxta possibilitatem uel iuxta neccessitatem suscipi|encium ea. Hijs cont $<\mathrm{em}>$ perant $u \mathrm{r}$ aduersitates . lux et tene $\mid$ bre . prelia et aduersiones . et breuiter dicere angustant hec atque hoc signum profectus hominis per auxilium dei . I De ${ }^{75}$ temptacionibus superborum ${ }^{76}$ TEmptaciones ${ }^{77}$ | itaque que fiu $n$ t a permissione dei contra imprude $n \mid$ tes et extollentes se in mentibus suis coram | bonitate dei in superbia sua sunt iste Tempta|ciones demonum manifeste que sunt supra po|tenciam anime . defectus virtutum sapiencie que sunt | in eis . sensualitas acuta intencionis fornicandi | que permittitur contra eos ad humilitatem elacionis eorum. I indignari cito . velle statuere propriam voluntatem . I litigare sermonibus. increpare et contempnere . error | mentis totalis . $\{\{\mathrm{p}\}\}^{78}$ blasphemia contra nomen dei . | intenciones fatue plene risu ymmo planctu . con | tempni ab omnibus . destruccio honoris sui fieri confu $\mid$ sio et obprobrium in modis multis a demonibus /f. 70v/ occulte manifesteque desiderium commisceri et conuersari | in mundo. loqui et nugari semper etinsipienter. adinuenire | sibi renouacionem semper cum falsa prophecia . promittere $\mid$ multa supra posse suu $m$. hec quidem sunt anime Jn cor|poralibus vero contingunt ei dolorosi euentus permane $n \mid$ tes semper perplexi vixque solubiles . occursus malorum | semper et impiorum hominum incidere in manus hominum trbula $n \mid$ cium . in ocio cordis semper sine causa ex repentino | timore parati multociens

${ }^{66}$ PG 86, c. XIII, coll. 828 (1. 21) - 829 (1. 10).

${ }^{67} \mathrm{Na}$ margem externa: <ysaac . .>.

68 PG 86, c. XIV, col. 830 (11. 23-33).

${ }^{69}$ PG 86, c. XIV, col. 830 (11. 40-47).

70 PG 86, c. LIII, col. 884 (11. 7-9).

${ }^{71} \mathrm{Na}$ margem externa: <ysaac>.

$72<\mathrm{T}>$ capitular.

73 PG 86, c. XLI, col. 870 (11. 48-55).

${ }^{74} \mathrm{Na}$ margem externa: < ysaac $>$.

${ }^{75} \mathrm{Na}$ margem externa: < ysaac . $>$.

${ }^{76}$ Este título aparece depois de TEmptationes nesta mesma linha mas foi antecipado aqui para melhor compreensão do leitor.

$77<\mathrm{T}>$ capitular.

${ }^{78}$ Letra incompleta e riscada. 
minas magnas ex la|pidibus et altis locis .et hijs simllia que fiunt ad | corporis fraccionem . vltimo egestas sapiencie | nostrum cor ex diuina virtute ac spe fidei | sue . et ut cito dicantur quotquot impossibilia et supra | vires sunt inducuntur ei $\mid$ Hec autem quotquot superius | notauimus et $\operatorname{det} e r<\mathrm{m}>\mathrm{i}<\mathrm{n}>$ auimus demonis sunt temptacionum | superbie . apparet aute $m$ principiu $m$ in homine quando $\mid$ quis incipit se habere sapiente $m$ in oculis suis | et sic transmutatur in omnibus hijs malis secundum mensu|ram suscepcionis huiusmodi cogitacionum superbie A | speciebus ergo cogitacionum tuarum comprehende viam sub|tilitatis mentis tue Quod si videris aliquas ex | hijs temptacionibus commixtas cum alijs temptacionibus | que superius ante dicte sunt scito quod in quantum habes ex | istis in tantum supenbia tibi contingit ${ }^{79}$. Hec ysaac de siria .

\subsection{Cód. GB 8 155, Arquivo Histórico da Cidade (Colônia), f. 138r}

Apontamentos codicológicos e paleográficos: Papel - ca. $1420-1+161+1 \mathrm{ff}$ - 14,5 × 10,5 - Proprietário anterior: Frades da Ordem da Santa Cruz de Colônia Foliação moderna a lápis em arábico - Descrição completa: Vennebusch (1983, p. 8791).

Transcrição: /f. 138r12/ . ysaac de contemptu mundi . | Quj non elongat se a causis viciorum voluntarie eciam | inuitus trahitur ad peccatum ${ }^{80}$

\section{ENQUADRAMENTO DOS FRAGMENTOS NA TRADIÇÃO LATINA DA OBRA DE ISAAC DE NÍNIVE}

Diferentemente de testemunhos com a versão integral de uma obra, que permitem uma ampla colação das versões de um texto, fragmentos são mais difícieis de serem enquadrados em sua tradição, já que o material disponível é bastante curto. No caso dos testemunhos aqui editados há ainda um outro elemento complicador, que é o fato de serem fragmentos de partes diferentes da obra de Isaac. Há, no entanto, duas partes que se repetem em alguns fragmentos: os cc. LIII e XXIX na numeração da $P G 86^{81}$.

No que se refere ao c. LIII, apresenta-se aqui uma seleção de variantes relevantes para a discussão, contrastadas com a versão do cód. 311 de Arezzo, um dos mais antigos e mais completos dessa tradição (Laranjeira, 2018, p. 180-184), embora não isento de erros próprios (como no LC 6 abaixo):

79 PG 86, c. XLI, coll. 870 (1. 57) - 871 (1. 46).

80 PG 86, c. XI, col. 821 (1l. 17-18).

81 Cabe assinalar que esses dois capítulos que circularam junto com a obra de Isaac de Nínive, sendo considerados parte dela, são na verdade de outro autor: são de João de Dalyata, também conhecido como João Saba, e agregaram-se à obra de Isaac já pelo menos na tradução grega (Cambraia, 2018, p. 116). Miller (1984, p. XCI) informa que já apareciam junto à obra de Isaac na tradição siríaca (como no cód. Vatic. Syr. 125), mas não necessariamente sendo percebidos como parte da obra de Isaac. 


\begin{tabular}{|c|c|c|c|c|c|c|}
\hline Códice & 311 & XIV G 17 & C 631 & M I 159 & GB 80 $76^{82}$ & 996 \\
\hline Datação & XIII-XIV & $\begin{array}{c}\text { XIV } \\
\left(2^{\mathrm{a}} \text { met. }\right)\end{array}$ & $\begin{array}{c}\text { depois de } \\
1416\end{array}$ & $\begin{array}{c}\mathrm{XV} \\
\text { (último terço) }\end{array}$ & $\begin{array}{c}\text { XV } \\
\left(1^{\text {a }} \text { met. }\right)\end{array}$ & 1516 \\
\hline Origem & Itália & Rep. Tcheca & Suécia & Rep. Tcheca & Alemanha & França \\
\hline Ordem & $\begin{array}{l}\text { Camaldu- } \\
\text { lense }\end{array}$ & Agostiniana & Santa Brígida & $?$ & Santa Cruz & Franciscana \\
\hline LC 1 & loqui & loqui & loqui & loqui & - & proferre \\
\hline LC 2 & audaci & audaci & audaci & audaci & - & mordaci \\
\hline LC 3 & Sputum & $\times$ & $\times$ & $\times$ & - & Sputum \\
\hline LC 4 & aspirationes & suspiria & suspiria & suspiria & - & aspirationes \\
\hline LC 5 & gulose & gulam & gulose & gulose & - & gulose \\
\hline LC6 & $\begin{array}{l}\text { Quando } \\
\text { loquitur } \\
\text { socius } \\
\text { obuiantibus } \\
\text { (V2) }\end{array}$ & $\begin{array}{l}\text { Quando socius } \\
\text { tuus loquitur } \\
\text { obuiantibus } \\
\text { (V3) }\end{array}$ & $\begin{array}{c}\times \\
(\mathrm{V} 5)\end{array}$ & $\begin{array}{l}\text { cum socius tuus } \\
\text { loquitur ab } \\
\text { amantibus } \\
\text { (V4) }\end{array}$ & - & $\begin{array}{l}\text { Quando } \\
\text { loquitur } \\
\text { socius tuus } \\
\text { obuiantibus } \\
\text { (V1) }\end{array}$ \\
\hline LC 7 & diabolicum & dyabolicum & dyabolicum & diaboli & dyabolicum & diabolicum \\
\hline LC 8 & $\begin{array}{c}\text { omni } \\
\text { tempore }\end{array}$ & $\begin{array}{c}\text { omni } \\
\text { tempore }\end{array}$ & $\begin{array}{l}\text { omni } \\
\text { opere }\end{array}$ & $\begin{array}{c}\text { bono } \\
\text { et omitte }\end{array}$ & $\begin{array}{c}\text { omni } \\
\text { tempore }\end{array}$ & $\begin{array}{c}\text { omni } \\
\text { tempore }\end{array}$ \\
\hline LC 9 & $\begin{array}{l}\text { possessio- } \\
\text { num }\end{array}$ & $\begin{array}{l}\text { possessio- } \\
\text { num }\end{array}$ & $\begin{array}{l}\text { possessio- } \\
\text { num }\end{array}$ & $\begin{array}{l}\text { possessio- } \\
\text { num }\end{array}$ & $\begin{array}{c}\text { passio- } \\
\text { num }\end{array}$ & $\begin{array}{l}\text { possessio- } \\
\text { num }\end{array}$ \\
\hline
\end{tabular}

Quadro 1 - Variantes relativas ao c. LIII na numeração da PG 86.

Com base nas variantes identificadas no quadro acima é possível perceber que:

a) o cód. 996 não terá sido modelo para os códs. XIV G 17, C 631 e M I 159, em função dos erros separativos nos LCs 1 e 2, o que é compatível com as datações atribuídas;

b) os códs. XIV G 17, C 631 e M I 159 pertencem a um ramo comum em função dos erros conjuntivos nos LCs 3 e 4;

c) o cód. XIV G 17 não terá sido modelo para os códs. C 631 e M I 159, em função do erro separativo no LC 5;

d) o cód. C 631 não terá sido modelo para os códs. XIV G 17 e M I 159, em função do erro separativo relativo à variante 5 no LC 6;

e) o cód. M I 159 não terá sido modelo para os códs. XIV G 17, M I 159 e GB $8^{\circ} 76$, em função dos erros separativos nos LCs 7 e 8;

f) o cód. GB $8^{\circ} 76$ não terá sido modelo para todos outros códices não apenas pelo LC 9 como também por apresentar apenas parte do c. LIII.

É digno de menção, considerando as demais variantes (não apresentadas no quadro acima), que o testemunho que apresenta o maior acúmulo de erros é o cód. M I 159 e o que apresenta o menor acúmulo é o cód. 996, o que de certa forma confirma o postulado recentiores non deteriores de Pasquali.

No que se refere ao c. XXIX, apresenta-se aqui a seguinte seleção de variantes:

\footnotetext{
82 Os campos que apresentam um travessão indicam que o testemunho não possui o trecho em questão e os que apresentam um $\times$ indicam que o testemunho tem o trecho mas não a variante. As variantes consideradas não genuínas estão marcadas com itálico. No LC 6 há múltiplas variantes, tendo sido considerada genuína V1.
} 


\begin{tabular}{|l|c|c|c|}
\hline Códice & 311 & A XI 72 & C 631 \\
\hline Datação & XIII-XIV & XV & depois de 1416 \\
\hline Origem & Itália & Suíça & Suécia \\
\hline Ordem & Camaldulense & Cartuxa & Santa Brígida \\
\hline LC $\mathbf{1}$ & contricionis & perdicionis & perdicionis \\
\hline LC $\mathbf{2}$ & $\times$ & $\begin{array}{c}\text { sicut os tuum sanctissimum } \\
\text { repromisit }\end{array}$ & $\begin{array}{c}\text { sicut os tuum sanctissimum } \\
\text { repromisit }\end{array}$ \\
\hline LC $\mathbf{3}$ & ihesu christe & $\times$ & $\times$ \\
\hline LC $\mathbf{4}$ & Confixe & Crucifixe & Confixe \\
\hline LC $\mathbf{5}$ & bonorum & bonorum & beatorum \\
\hline LC $\mathbf{4}$ & odorem & odorem & ordinem \\
\hline
\end{tabular}

Quadro 2 - Variantes relativas ao c. XXIX na numeração da $P G 86$.

Com base nas variantes identificadas no quadro acima é possível perceber que:

a) o cód. 311 não terá sido modelo para os códs. A XI 72 e C 631 em função dos erros separativos nos LCs 1 e 2;

b) os códs. A XI 72 e C 631 pertencem a um ramo comum em função do erro conjuntivo no LC 3;

c) o cód. A XI 72 não terá sido modelo para os códs. 311 e C 631 em função do erro separativo no LC 4;

d) o cód. C 631 não terá sido modelo para os códs. 311 e A XI 72 em função dos erros separativos nos LCs 5 e $6^{83}$.

Por fim, é também relevante para o enquadramento dos testemunhos analisados assinalar que, como já comentado em nota, o cód. A X 102 apresenta, no c. XIII, uma inovação também presente no cód. 1838 da Biblioteca da Abadia de Melk (f. 203r16-18) (Cambraia; Laranjeira, 2010, p. 25), da ordem beneditina.

\section{CONSIDERAÇÕES FINAIS}

Apresentou-se aqui uma edição paleográfica de nove testemunhos fragmentários até então inéditos da tradução latina da obra de Isaac de Nínive.

A análise do conteúdo das versões da tradução latina da obra de Isaac de Nínive presentes nesses testemunhos sugere que se trate principalmente de registros terminais na linha de transmissão, uma vez que não apresentam relação de filiação direta entre si (nos casos em que veiculam versão dos mesmos capítulos). Foi, no entanto, possível detectar, em função de erros conjuntivos, certo grau de afinidade (a) entre os códs. XIV G 17, C 631 e M I 159 e (b) entre os códs. A XI 72 e C 631.

A ausência de relação de filiação direta entre os testemunhos analisados parece dever-se ao fato de serem mais tardios (de fins do séc. XIV a fins do séc. XV, enquanto a tradução terá sido realizada antes de 1270), mas também porque pertenceram a ordens monásticas diferentes (agostiniana, franciscana, de Santa Brígida, cartuxa e da Santa Cruz).

Este trabalho contribuiu também para a identificação de novos lugares críticos na tradição latina da obra de Isaac de Nínive, ampliando assim a lista de lugares críticos

${ }^{83}$ Nos item (c) e (d), a menção ao cód. 311 é de certa forma redundante, já que, sendo C 631 e A XI 72 testemunhos fragmentários, não poderiam ser modelo para o cód. 311, testemunho com texto integral. 
já conhecidos na tradição latino-românica dessa obra (Meyer; Burckhardt, 1966; Cambraia, 2000, 2002, 2005a, 2011, 2017, 2018, 2020; Cambraia; Laranjeira, 2010; Cambraia; Melo; Vilaça, 2008-2009; Cambraia; Avellar, 2017).

\section{REFERÊNCIAS}

Andersson-Schmitt M, Hallberg H, Hedlund M. Mittelalterliche Handschriften der Universitätsbibliothek Uppsala: Katalog über die C-Sammlung. Band 6. Handschriften C 551-935. Stockholm: Almqvist \& Wiksell International; 1993. [citado 23 out. 2019]. Disponível em: http://bilder.manuscripta-mediaevalia.de/hs//kataloge/HSK0506f.htm.

Binz G. Die Handschriften der Öffentlichen Bibliothek der Universität Basel: Abt. 1, Bd. 1, Die deutschen Handschriften der Öffentlichen Bibliothek der Universität Basel. Abt. A. Basel: [Universitätsbibliothek]; 1907. [citado 23 out. 2019]. Disponível em: http://www.archive.org/details/p1diehandschrift01univuoft.

Boháček M, Čáda F. Beschreibung der mittelalterlichen Handschriften der Wissenschaftlichen Staatsbibliothek von Olmütz. Köln: Böhlau; 1994.

Brock S. From Qatar to Tokyo, by way of Mar Saba: the translations of Isaac of Beth Qatraye (Isaac the Syrian). Aram, 1999-2000;11-12:475-484. [citado 23 out. 2019]. Disponível em: http://dx.doi.org/10.2143/ARAM.12.0.504483.

Cambraia CN. Livro de Isaac: edição e glossário (cód. ALC 461) [tese]. São Paulo: Faculdade de Filosoia, Letras e Ciências Humanas, Universidade de São Paulo; 2000.

Cambraia CN. A difusão da obra de Isaac de Nínive em línguas ibero-românicas: breve notícia das tradições portuguesa, espanhola e catalã. In: Ravetti G, Arbex M. (Org.). Performance, exílio, fronteiras: errâncias territoriais e textuais. Belo Horizonte: Departamento de Letras Românicas da Faculdade de Letras da UFMG/PosLit; 2002. p. 293-315.

Cambraia CN. Contributo ao estudo da tradição latina do «Livro de Isaac»: o cód. ALC 387 da Biblioteca Nacional de Lisboa. Scripta Philologica, 2005a;1:1-10.

Cambraia CN. Introdução à crítica textual. São Paulo: Martins Fontes; 2005b.

Cambraia CN. Diálogo entre tradição direta e indireta: variantes da tradução latina da obra de Isaac de Nínive no Tractatus Pauperis de John Pecham. Letras Clássicas, 2011;15:9-37. [citado 23 out. 2019]. Disponível em: https://doi.org/10.11606/issn.2358-3150.v0i15p9-37.

Cambraia CN. Livro de Isaac (cód. 50-2-15 da BN): caminhos percorridos. Anais da Biblioteca Nacional, 2013-2014;133-134:15-35. [citado 23 out. 2019]. Disponível em: http://memoria.bn.br/pdf/402630/per402630_2013-2014_133-134.pdf.

Cambraia CN. Livro de Isaac: edição crítica da tradução medieval portuguesa da obra de Isaac de Nínive. Belo Horizonte: Editora UFMG; 2017.

Cambraia CN. Do Isaac de João Cassiano ao Isaac de Nínive: processos de incorporação textual na tradição latina. Classica: Revista Brasileira de Estudos Clássicos, 2018;31:113-128. [citado 23 out. 2019]. Disponível em: https://doi.org/10.24277/classica.v31i2.704.

Cambraia CN. Edição paleográfica sinóptica da tradição latino-românica da obra de Isaac de Nínive: uma fonte para os estudos românicos. In: Fachin PRM, Monte VM do. (Org.). Pesquisas em andamento: caminhos pela filologia e pela história e historiografia do português. São Paulo: FFLCH-USP; 2020. p. 7-23. [citado 11 dez. 2020]. Disponível em: http://www.livrosabertos.sibi.usp.br/portaldelivrosUSP/ catalog/view/500/451/1738-1. 
Cambraia CN, Avellar JB de C. Um ensaio de estemática: tradição ibero-românica da obra de Isaac de Nínive. Revista da Abralin, 2017;16(1):15-36. [citado 23 out. 2019]. Disponível em: http://dx.doi.org/10.5380/rabl.v16i1.51875.

Cambraia CN, Laranjeira MB. Tipologia dos erros na tradição latina do «Livro de Isaac». Caligrama: Revista de Estudos Românicos, 2010;15:7-48. [citado 23 out. 2019]. Disponível em: http://dx.doi.org/10.17851/2238-3824.15.2.7-48.

Cambraia CN, Melo TCA de, Vilaça C de L. Tradição latino-românica do Livro de Isaac: análise de lugares-críticos. Filologia e Linguística Portuguesa, 2008-2009;10-11:409-425. [citado 23 out. 2019]. Disponível em: https://doi.org/10.11606/issn.2176-9419.v0i10-11p409-425.

Chialà S. Dall'ascesi eremitica alla misericordia infinita: ricerche su Isaaco di Ninive e la sua fortuna. Firenze: Leo S. Olschki; 2002.

Laranjeira MB. De contemptu mundi et de contemplationis perfectione (cód. 311 da Biblioteca Città di Arezzo): edição e confronto com a edição da Patrologia Graeca (1865) [dissertação]. Belo Horizonte: Faculdade de Letras, Universidade Federal de Minas Gerais; 2018. [citado 23 out. 2019]. Disponível em: https://repositorio.ufmg.br/bitstream/1843/LETR-B97FKA/1/1989m.pdf.

Meyer G, Burckhardt M. Die mittelalterlichen Handschriften der Universitätsbibliothek Basel. Beschreibendes Verzeichnis. Abteilung B: Theologische Pergamenthandschriften. Zweiter Band: Signaturen B VIII 11 - B XI 26. Basel: Verlag der Universitätsbibliothek; 1966. [citado 23 out. 2019]. Disponível em: http://bilder.manuscripta-mediaevalia.de/hs//kataloge/HSK0503b.htm.

Migne JP. Patrologiae cursus completus: series latina. Paris: Ed. de l'Auteur; 1849. T. 77. [citado 23 out. 2019]. Disponível em: http://books.google.com/books?id=ApBBAAAAcAAJ.

Migne JP. Patrologiae cursus completus: series latina. Paris: Ed. de l'Auteur; 1854. T. 176. [citado 23 out. 2019]. Disponível em: https://books.google.com.br/books?id=-cY_AQAAMAAJ.

Migne JP. Patrologiae cursus completus: series latina. Paris: Ed. de l'Auteur; 1855. T. 194. [citado 23 out. 2019]. Disponível em: https://books.google.com.br/books?id=dPMQAAAAYAAJ.

Migne JP. Patrologiae cursus completus: series graeca prior. Paris: Ed. de l'Auteur; 1865. T. 86, p. 1. [citado 23 out. 2019]. Disponível em: http://books.google.com/books?id=SpPYAAAAMAAJ.

Miller D. (Tr.) The ascetical homilies of St. Isaac the Syrian. Boston: The Holy Transfiguration Monastery; 1984.

Molinier A. Catalogue des manuscrits de la Bibliothèque Mazarine. Paris: E. Plon, Nourrit et Cie; 1885. T. 1. [citado 23 out. 2019]. Disponível em: https://archive.org/details/cataloguedesman01moligoog.

Munitz J. A greek Anima Christi prayer. Eastern Churches Review, 1974;6(2): 170-180.

Saxonia L de. Vita Jesu Christi. Ed. de L.-M. Rigollot. Paris/Roma: Victorem Palme/Livraria S. Congreg. de Propaganda Fide; 1870. [citado 23 out. 2019]. Disponível em: https://books.google.com.br/books?id=Th4XAAAAYAAJ.

Truhlář J. Catalogus codicum manu scriptorum latinorum. qui in c. r. bibliotheca publica atque Universitatis Pragensis asservantur. Pragae: Regiae Societatis Scientiarum Bohemicae; 1906. Pars posterior. [citado 23 out. 2019]. Disponível em: https://archive.org/details/cataloguscodicu01prazgoog.

Vennebusch J. Die theologischen Handschriften des Stadtarchivs Köln, Teil 3. Die OktavHandschriften der Gymnasialbibliothek. Köln; Wien: Böhlau; 1983. [citado 23 out. 2019]. Disponível em: http://bilder.manuscripta-mediaevalia.de/hs//kataloge/HSK0039.htm. 